
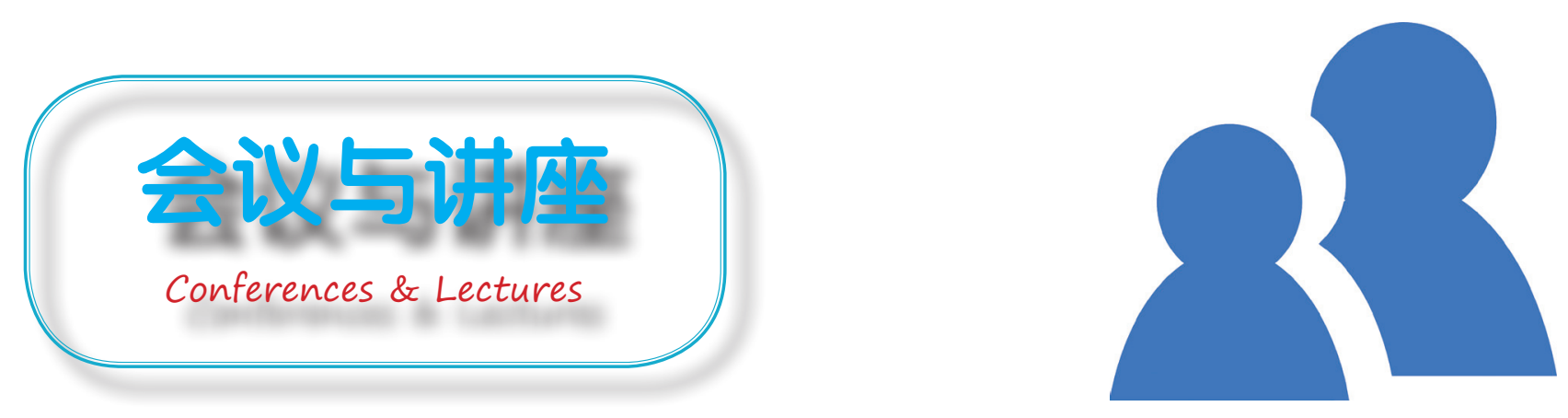

\title{
知名药企再启学术推广新模式, 使更多医学科研人员受益
}

\section{杨永芳}

\section{武汉美捷登生物科技有限公司}

为期 3 天的河北儿科学术年会于 2018 年 8 月 24-26日在唐山召开。借此盛会, 以原创药“优舒芬(右 旋布洛芬) 而闻名全国的湖北唯森制药有限公司在 8 月 25 日举办了 “儿童退热安全用药暨高质量学术论 文撰写研讨会”全国巡讲活动。本次大会主席、中华 医学会儿科分会委员、河北省医学会儿科学分会主 任委员安淑华教授为本次巡讲致开幕辞 (图 1)。
这是湖北唯森公司今年第三次举办 “儿童退热 安全用药暨高质量学术论文撰写研讨会”, 也是第 三次邀请美捷登 (Medjaden) 和华誉出版社 (Xia \& He Publishing Inc.) 董事长、中国英文科技论文 编辑联盟 (Alliance of Scientific Editing in China, ASEC) 发起人及首任理事长夏华向教授担任主讲嘉 宾 (图 2)。会议人数也从首次的 70 多人增至本次约

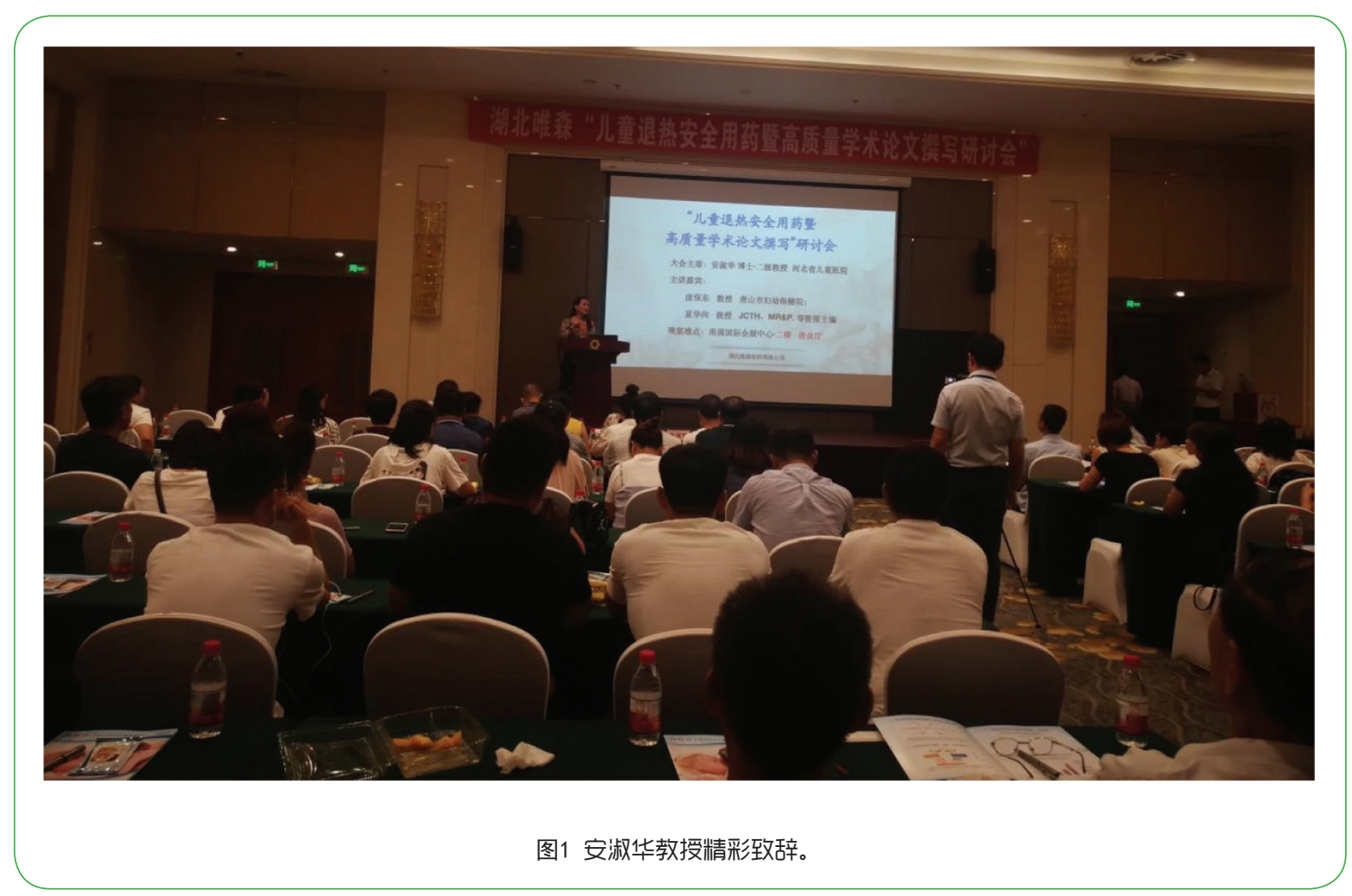




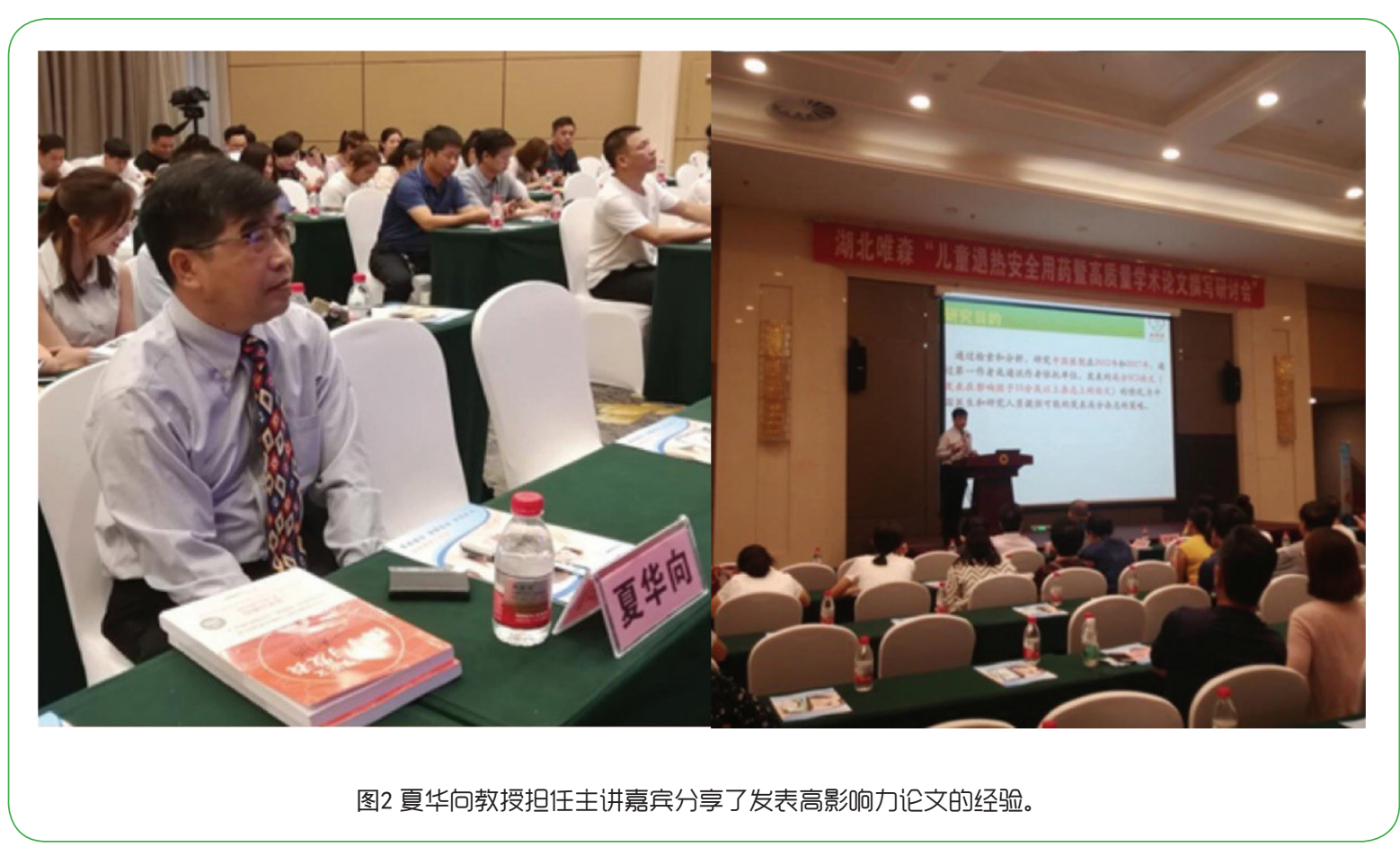

200 多人。可以说, 唯森公司的这种 “学术推广新模 式”效果显著。该公司主管销售的副总经理刘铁强先 生对此表示非常满意, 他欣慰地说: “河北市场打开 了, 销售就不应该有问题!”。

研讨会上, 夏教授为儿科医学工作者介绍了近
10 年内中国 SCI 论文数量逐年增长的趋势, 分析了 2012 年到 2017 年这 5 年间通过第一作者或通讯作者 依托单位发表高分 SCI 论文的情况，再结合个人实 例为中国医生和研究人员提供可能的发表高影响力论 文的策略。在场的医学科研人员纷纷表示收获颇丰,

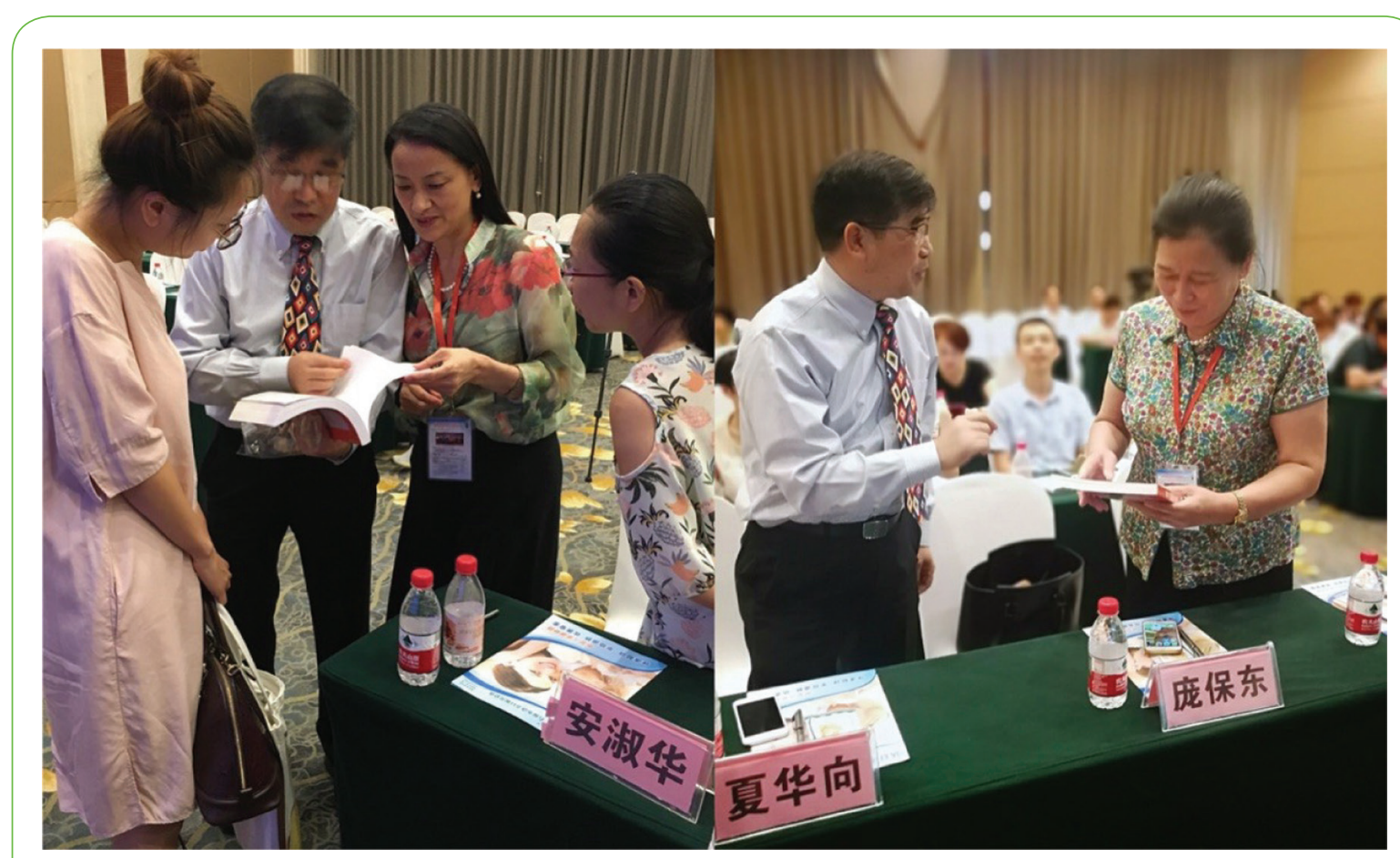

图3 夏华向教授向安淑华教授（左）和庞保东教授(右)介绍著作《英文医学论文撰写与发表一本通》。 
正可谓 “听君一席话, 胜读十年书”。

会议期间，夏教授分别向安淑华教授和华北煤 炭医学院主任医师, 河北省医学会儿科分会秘书、 唐山市医学会儿科分会主任委员、本次研讨会另一位 主讲嘉宾庞保东教授详细介绍并赠予了新作《英文 医学论文撰写与发表一本通》(图 3)。
一次合作是尝试, 二次合作是肯定, 三次合 作便是十足的信任! 美捷登与药企的这种学术合 作模式在湖北唯森得到充分的验证。在未来的 日子里, 美捷登将继续总结和推广这种与药企合 作的新模式, 使更多药企和医学科研人员同时受 益!

\title{
让临床与科研齐头并进，这家医院正在做！
}

\section{杨永芳}

\author{
武汉美捷登生物科技有限公司
}

9月 4 日, 广州市第一人民医院南沙医院籍开业 十周年之际, 为大力提升临床科研水平, 建设南沙 医学科研新高地, 特邀夏华向教授做客 “庆开业十 年南沙医学大讲堂”。大讲堂由广州市第一人民医院 南沙医院副院长蔡维山主持, 院长贾林教授致开幕词 (图 1)。

近 200 位来自南沙中心医院和南沙区其他医 院的医务人员慕名而来 (图 2)。首先, 夏教授做了 《青年医师科研成长之路及撰写发表英文文章之技 巧》学术讲座。参加学习的医务人员认真听讲并做 笔记 (图 2)。讲座结束后, 贾林院长总结: “夏教 授的讲座恰逢其时”, 值南沙中心医院开业十周年 之际, 特邀夏华向教授开展 “青年科研成长之路”
专题讲座的目的, 是基于青年职工晋升和职业生涯 发展需要, 同时也是学科发展和南沙医学科研高地 的建设所需, 打破医院医务人员科研、创业精神有 所淡化的不良局面。夏教授以自己的亲身经历讲述 如何步入医学殿堂、如何外出留学、如何创建了美 捷登等。他的精彩演讲和现身说法不仅展示了一个 有为青年的成长之路, 而且有力地激发了大家的科 研热情和不断进取的勇气, 促进临床与科研兼顾 发展, 有助于培养 “能文能武、能研能写” 的医学 专家。

随后, 贾院长主持了以 “如何撰写科研论文”为 主题的座谈会。医院科研骨干和研究生们积极与夏 教授展开充分交流。夏教授针对大家在医学科研和

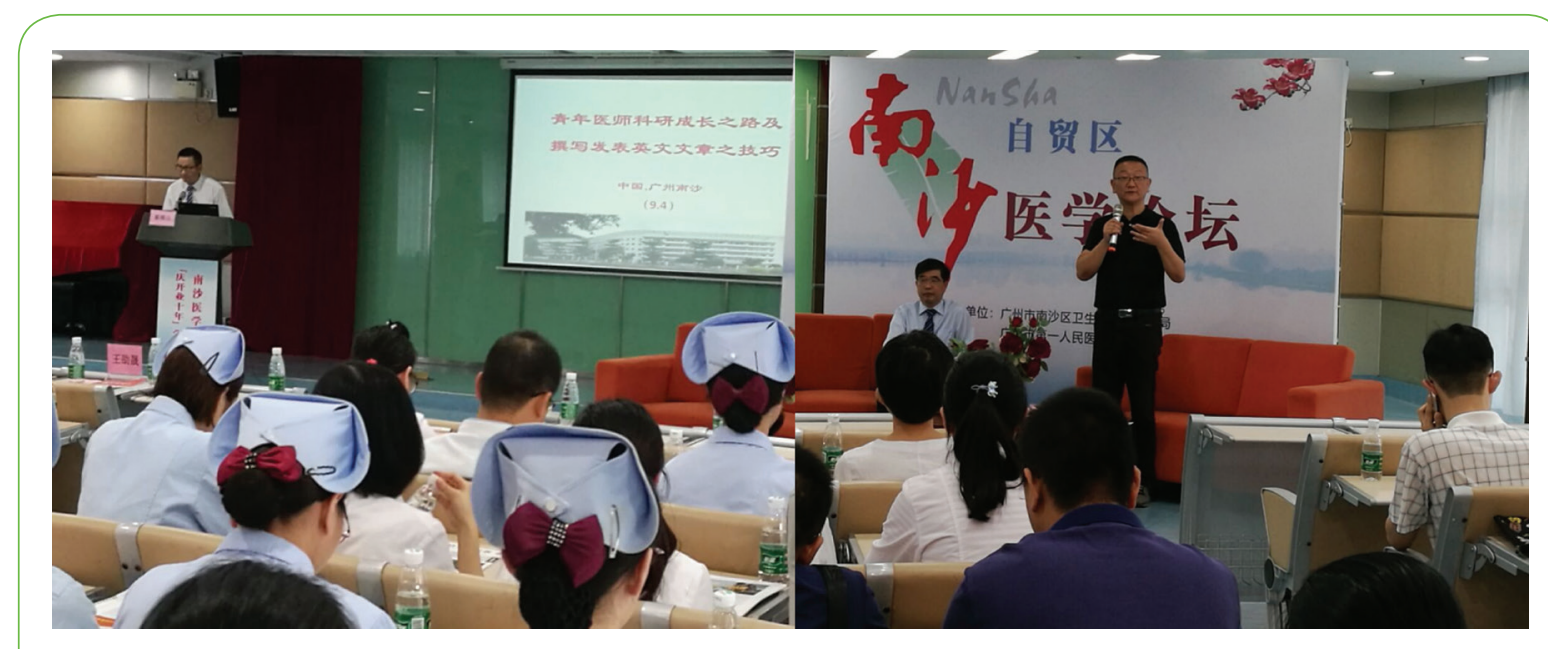

图1 蔡维山副院长(左)和贾林院长(右)主持。 


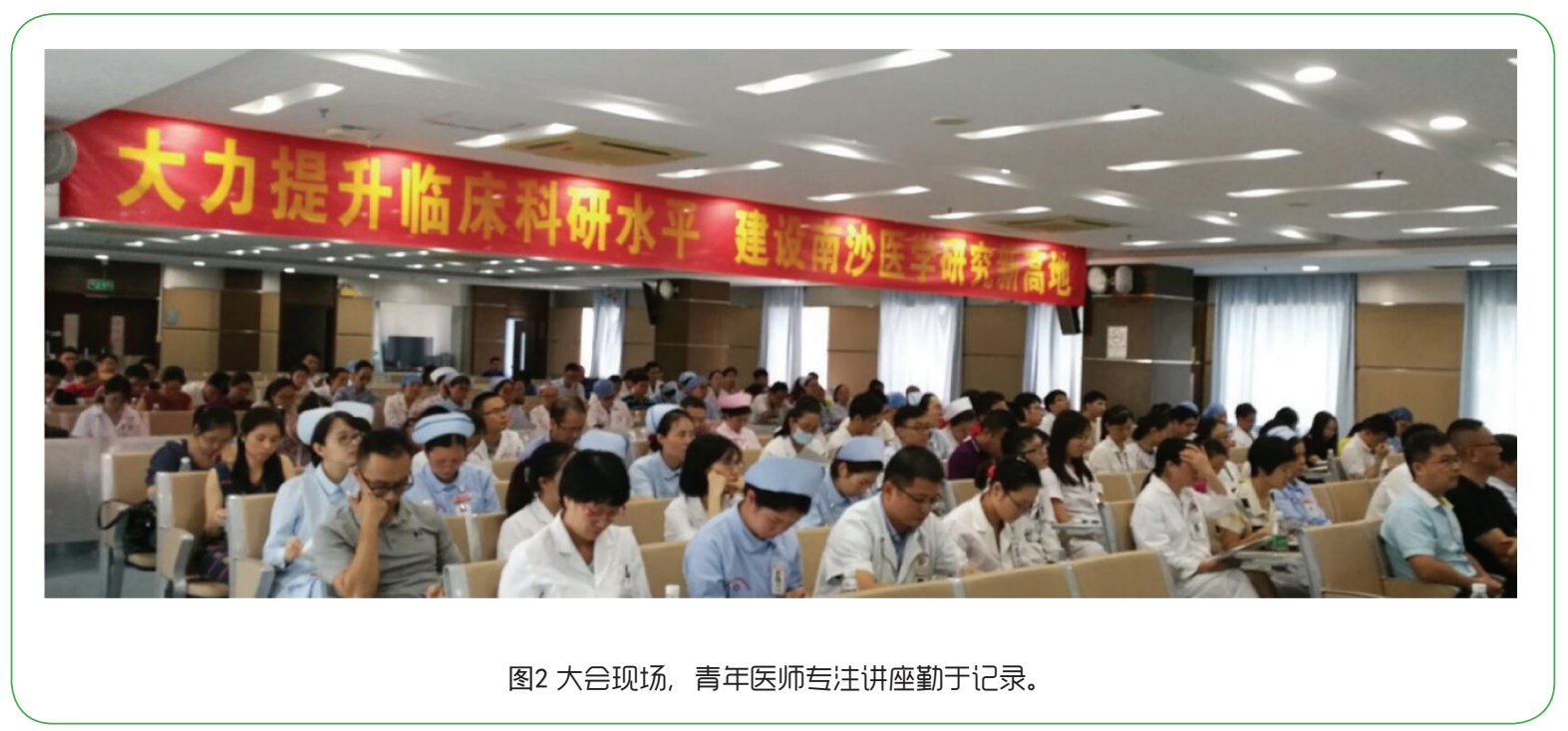

撰写科研论文 (尤其是英文论文) 中具体存在的主 要问题和困惑, 一一做了详细解答。现场气氛活跃、 提问不断 (图 3)。这种大范围讲座教授理论知识结 合小范围座谈解答具体问题的教学模式更有效满足 了不同层次科研人员的需求。贾林院长现身说法也 说明了临床与科研可以齐头并进和相互促进。座谈 会一直持续到 17:40 分结束。

9 月 5 日下午，夏教授在广州第一人民医院进行 了由该院副院长聂玉强教授主持的《医学研究与 SCI 论文撰写》主题学术讲座。夏教授从“生物医学论文
的素材来源、生物医学论文的题材来源、中国科研 人员医学研究与发表常见问题与学术不端行为预防” 四个方面向近 200 名听众详细讲述了医学研究与 SCI 论文撰写中经验、技巧、问题和预防学术不端行为 及嫌疑的方法。

两天的学术活动激发了广州市第一人民医院及 其南沙医院医科研人员医学研究与医学论文撰写和 发表的热情。每天的学术活动之后, 夏教授将其新 作《英文医学论文撰写与发表一本通》赠送给该院图 书馆和科研骨干和 (图 4)。

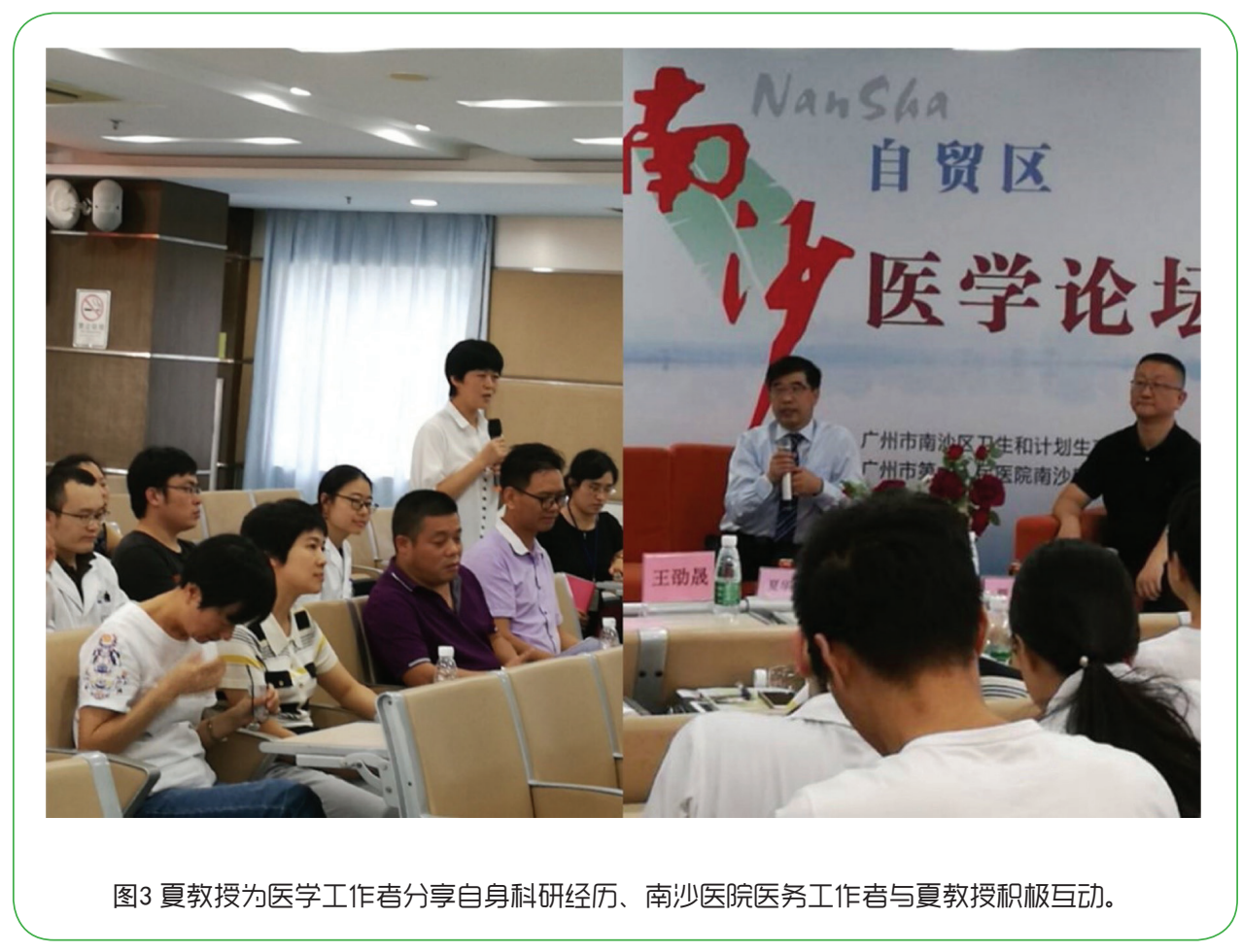




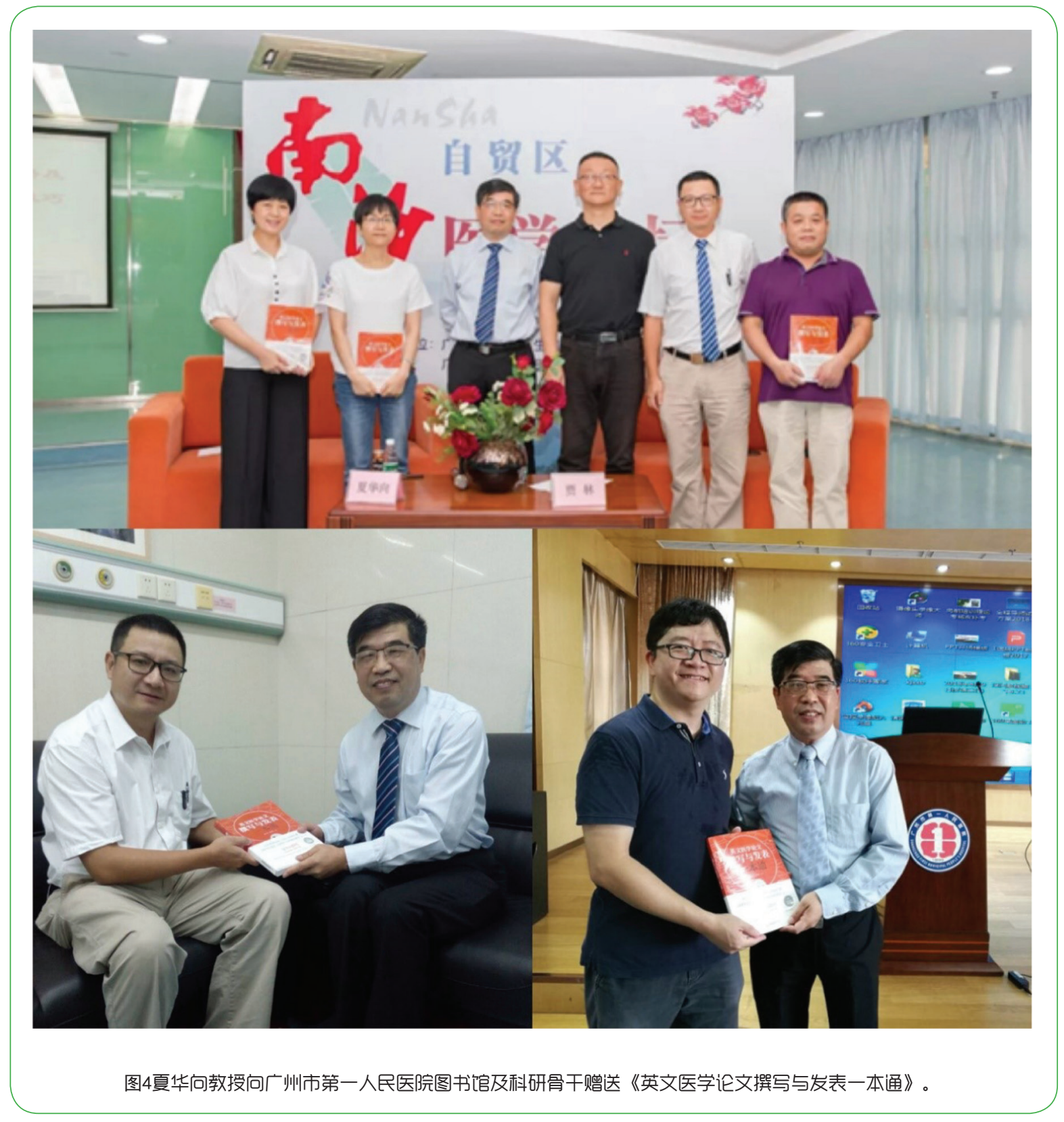

